calcium chromosphere under the balance of gravitational forces and radiation pressure. He discovered that for varying radiation from below the equilibrium was unstable, so that in certain circumstances atoms could ultimately be ejected from the sun with terminal speeds of the order of $1,600 \mathrm{~km}$. per sec.

Milne's numerous memoirs on the opacity of stellar atmospheres culminated in his Bakerian Lecture of 1929. In the same year Milne took up his duties at Oxford, and during the following three years devoted his main energies to elaborating a theory of stellar structure based on a constructive mathematical criticism of the pioneer researches of Sir Arthur Eddington. In 1932 he delivered the Halley Lecture on "The White Dwarf Stars".

Meanwhile his interest had been aroused in the theory of the expanding universe, and in May 1932 he began that train of investigation which became the most original, the most controversial and the most far-reaching of the many theories associated with his name. He devised a new world-model which in its augmented form with a 'statistical component' appeared to be more fruitful than any of the homogeneous models hitherto produced by the 'orthodox' relativistic cosmologists. In particular, it provided an astonishingly simple explanation of Hubble's law correlating distance and velocity of recession, and also a possible gravitational explanation for the origin of cosmic rays.

Nevertheless, it is probable that that part of Milne's work in cosmology and relativity which will prove of the most lasting significance is the theory of time measurement by equivalent observers, on the basis of which new deductive systems of dynamics, gravitation and electrodynamics were developed in rapid succession. Associated with this work were two fundamentally novel ideas: the conception of different uniform scales of time operating in Nature, and the idea which first emerged from my analysis, arising out of Milne's generalization of my derivation of the Lorentz formulæ (itself suggested by remarks of Milne), that the fundamental group of equivalent frames is more restrictive than the six-fold infinite group of Newtonian and special relativity physics. The latter idea was explored further by Milne in his final contribution to the Proceedings of the Royal Society last year; but much still remains to be done.

It is impossible to convey here any detailed impression of Milne's many other contributions to stellar kinematics and dynamics, the kinematics and structure of spiral nebulæ, the theory of cepheid variation, etc. ; it was characteristic of his courage that, although he knew his health was precarious, he made the journey to Dublin to read an exciting new paper on a relation, akin to Blackett's, connecting gravitation and magnetism, which had emerged from recent dovelopments in kinematic relativity.

Apart from innumerable original memoirs, Milne published a long chapter on "The Thermodynamics of the Stars" in the "Handbuch der Astrophysik" in 1930 and three books : "Relativity, Gravitation and World-Structure" in 1935, "Kinematic Relativity" and "Vectorial Mechanies", both in 1948. He leaves two further books in manuscript : a life of Sir James Jeans, to be published by the Cambridge University Press, and a course of lectures which he was to have delivered at Birmingham this winter on the Edward Cadbury Foundation. $\mathrm{He}_{\theta}$ was also editor of the mathematical and physical sciences section of the series "Hutchinson's University Library".
Milne received many academic honours. He was elected a fellow of the Royal Society in 1926 at the age of thirty. He was awarded the Gold Medal of the Royal Astronomical Society in 1935, a Royal Medal of the Royal Society in 1941, and the Bruce Medal of the Astronomical Society of the Pacific in 1945. He was president of the London Mathematical Society during 1937-39, and president of the Royal Astronomical Society during 1943-45. He became an honorary member of the American Astronomical Society, a foreign honorary member of the American Academy of Arts and Sciences, both in 1947, and an honorary member of the Calcutta Mathematical Society in 1948. He was a D.Sc. (Oxon.) and an hon. D.Sc. (Amsterdam).

Milne was married twice. By his first wife, Margaret Scott (daughter of Hugh Fraser Campbell, of Dornoch, Sutherland), who died in 1938, he leaves two daughters and a son; by his second wife, Beatrice Brevoort (daughter of William Whotten Renwick, of New York), who died in 1945, he leaves a daughter.

Small in stature, Milne was outstanding in every other way. His penetrating and original intellect was sustained throughout many personal misfortunes by remarkable courage and unshakable religious conviction. Despite his brilliance of mind and widespread recognition, he retained a great humility and simplicity of character. To his research students, particularly to those of us who knew him in his prime, he was an unfailing source of inspiration. He was always the kindest and most conscientious of supervisors and collaborators. We mourn the passing of a leader among men of science and a pioneer among philosophers of Nature. G. J. Whitrow

\section{Dr. D. H. Bangham}

Physical chemistry, and perhaps more specifically fuel technology, have suffered a grievous loss by the death on July 29, at the early age of fifty-five, of Dr. Donald Hugh Bangham, director of Research Laboratories, British Coal Utilisation Research Association. His health had not been good for some little time; but his end came rather suddenly and as a sad blow to his immediate colleagues.

The quality of his mind was evident at an early age ; in 1912 he won a scholarship in natural science to Jesus College, Oxford. Two years later he was commissioned in the King's (Liverpool) Regiment, attaining the rank of captain and gaining the Military Cross for leading an attack on the Hindenburg Line defences. Shortly after returning to academic life, he graduated with first-class honours and was appointed (1919) lecturer in physical and inorganic chemistry in the University of Manchester, where he published a number of papers concerned with rateprocesses at the gas-solid interface ; he revealed two characteristics : careful and elegant technique and a great power of generalization.

In 1926 Bangham accepted the chair of physical and inorganic chemistry in the newly founded Faculty of Science in the University of Cairo, where he was faced with the task of planning and equipping the laboratories, as well as preparing curricula. He served as dean of the Faculty during 1927-36, and on returning to England in 1937 he was awarded the Order of the Nile with the rank of commander.

Bangham joined the staff of the British Coal Utilization Research Association in 1938, almost at 
its inception, and played a prominent part in recruiting scientific personnel and initiating their work. During the following twelve years he displayed outstanding leadership in researches concerned with the physical structure of coal and with the mechanism of its combustion. Previous approaches had been made by the analytical chemist and the geologist; Bangham followed the line that bright coal wäs a solid colloid, or an assembly of small particles too small to be visible under the microscope and imparting to the lump a porous structure. This conception has led to a model adequately accounting for the variation with rank of the properties of different coals. It has also been of great assistance in elucidating the complicated phenomena associated with solid fuels undergoing combustion; for example, 'reactivity'.

Two days before he died, Bangham was able to peruse a new work, "Progress in Coal Science", which he had edited ; this work is a fitting memorial to his great ability and activity in editing for publication the considerable output of the British Coal Utilization Research Association.

Barigham was a great gentleman and a loyal colleague, whole-heartedly devoted to science and its industrial applications; and he gave much in exchange for little. Towards the end he fought against ill-health with a gallantry that evoked the esteem of all who knew him intimately; and he will be sorely missed. He leaves a widow, two sons and a daughter.

D. T. A. TOWNEND

\section{Mr. William Birtwhistle}

MaNy visitors to the Cavendish Laboratory will have met Willie Birtwhistle, whose death occurred on September 25. For the past twenty years he had cared for the high-voltage accelerator of the Labora. tory. He was trained in electrical engineering, and we were fortunate in being able to bring him to Cambridge when we started to build our proton accelerator in 1930. We had to instal a high-voltage transformer and exciting equipment, to build a voltage multiplying rectifier and accelerating tubes, and to apply the new technique of fast oil-diffusion pumps to our work. In all of this, Birtwhistle played a major part. A good deal of time had to be spent on finding leaks in the numerous seals which were then made by the use of low vapour-pressure 'Plasticine' developed for the work, and we will always remember the patience and care with which Birtwhistle thumbed the joints until the diffusion-pump spark discharge turned from pink to green and then finally to black.

In all the experimental work during 1932-37 with Dee, Gilbert, Lewis, Walton and myself, Birtwhistle took a full part. He always used to know what an experiment was about without being told, and he had always a very good sense of what was wrong when any trouble developed.

When the new high-voltage laboratory of the Austin Wing was built, he moved to the new laboratory and built and installed to Dee's design the onemillion volt accelerating tube which worked with the Philips cascade generator. During the difficult years of the War the laboratory was kept going steadily for the work of the atomic energy project, and the return to academic work in 1945 was greatly helped by the loving care with which it had been tended.

Birtwhistle was a typical north countryman with a quiet humour and Yorkshire accent which was a pleasure to listen to. His patient ways and sound experimental sense inspired confidence in research students and helped many of them over their diffculties. He was a keen collector of stamps, and many research students who went overseas added to his collection.

Experimental physics owes much to its research assistants, and Willie Birtwhistle will take his place in their honoured roll."

J. D. COCKCrofT

WE regret to announce the following deaths :

Sir Sidney Harmer, K.B.E., F.R.S., director of the British Museum (Natural History) during 1919-27, on October 22, aged eighty-eight.

Prof. S. Sugden, F.R.S., professor of chemistry at University College, University of London, on October 20 , aged fifty-eight.

Prof. Emil Votoček, emeritus professor in the Czech Institute of Technology, Prague, known for his work in organic chemistry, on October 11, aged seventy-eight.

\section{NEWS and VIEWS}

\section{Cedergren Medal for 1949 : Prof. R. Rüdenberg}

Prof. Reinhold RÜDEnberg, Gordon McKay professor of electrical engineering in Harvard University, has been awarded the gold Cedergren Medal and Scroll for 1949 for highly meritorious work in the field of electrical engineering. The Medal was founded by the Stockholm General Telephone Co. in memory of Henrik Tore Cedergren, director of telephony, and is awarded every five years for work in the art and science of electricity by the Royal governors for the universities of technology in Sweden. Prof. Rüdenberg, who is the eighth recipient of the Medal, was born in Hannover in 1883 and studied engineering at the Hannover Institute of Technology. He was an honorary professor at the Institute of Technology in Charlottenburg while he worked as chief electrical engineer of Siemens-Schuckertwerke in Berlin during 1923-36. He went to Harvard in 1939. In 1912 Prof. Rüdenberg was awarded the Montefiore Prize of the
University of Liège for research on commutator machinery and in 1946 received an honour award medallion from the Stevens Institute of Technology for his work in connexion with the invention of the electron microscope.

\section{Names of Chemical Elements}

Tre names of chemical elements have been under consideration at the fifteenth congress of the International Union of Pure and Applied Chemistry which took place in September 1949 at Amsterdam. The report of the Congress is now available (Siège de l'Union, 28 Rue Saint-Dominique, Paris, 7e). The Commission on Inorganic Chemical Nomenclature made the following recommendations, which were adopted by the Union, for the newly discovered elements : Element 43 should be called 'Technetium' (Tc), 61 'Promethium' (Pm), 85 'Astatine' (At), 87 'Francium' (Fr), 93 'Neptunium' (Np), 94 'Plutonium' 